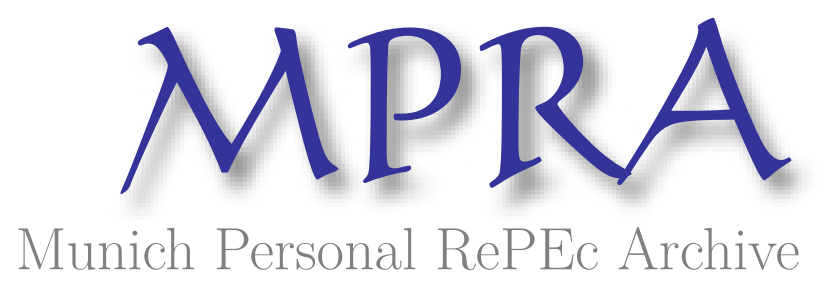

\title{
Causes and Consequences of Inflation
}

Bagus, Philipp and Gabriel, Amadeus and Howden, David

2014

Online at https://mpra.ub.uni-muenchen.de/79608/

MPRA Paper No. 79608, posted 09 Jun 2017 04:57 UTC 
This article can be cited as: Bagus, Philipp, David Howden and Amadeus Gabriel. 2014. "Causes and Consequences of Inflation." Business and Society Review 119(4): 497-517.

It can be found at: http://onlinelibrary.wiley.com/doi/10.1111/basr.12043/abstract

\title{
Causes and Consequences of Inflation ${ }^{1}$
}

\author{
Philipp Bagus \\ Associate Professor of the Economics Department \\ Universidad Rey Juan Carlos \\ Madrid, Spain \\ philipp.bagus@urjc.es \\ David Howden \\ Professor of Economics \\ St. Louis University \\ Madrid, Spain \\ dhowden@slu.edu \\ Amadeus Gabriel \\ Assistant Professor \\ Department of Finance and Economics \\ La Rochelle Business School \\ La Rochelle, France \\ gabriela@esc-larochelle.fr
}

\begin{abstract}
While ethical implications of direct taxation systems have recently received renewed attention, a more veiled scheme remains unnoticed: inflation. We overview the causes of inflation and assess its consequences. Salient wealth redistributions are a defining feature of inflation, as savers and fixed income individuals see a relative wealth reduction. While avoiding this "tax" is difficult in many instances due to the primacy of money in a monetary economy, the tax codes of most developed countries allow avoidance techniques to be employed. We analyze three ways that inflation may be avoided in an attempt to preserve personal wealth, as well as the consequences of such practices.
\end{abstract}

Keywords: inflation, taxation, costs of inflation, price stability 


\section{Causes and Consequences of Inflation}

\section{Introduction}

Much recent literature focuses on the ethics of direct taxation (Joel Slemrod 2007; Bagus et al. 2011; Robert W. McGee 2012c). Whether income and consumption taxes are imposed coercively on both consumers and producers has long been contested. This being as it may, taxes can be, and often are, remitted to the government voluntarily as if they were not reliant on their coercive imposition. In this case we are led to believe that there is no difference between taxation and voluntarily donations of money to the government -both will result in spending that is consistent with taxpayers' desires. The curiosity that arises is that if people did donate money voluntarily to the government, neither coercion or taxation would be necessary. This has led some to deem taxation as an inefficient and involuntary disruptor of the process of economic calculation (Bagus et al 2011). ${ }^{2}$

While effects from the system of direct taxation have been adequately addressed, there is a more obscure, if ubiquitous, form of taxation affecting all market participants. Inflation- that loss of purchasing power savers suffer as a result of inflationary monetary policies - is another means of government finance. The government acquires resources in both cases of taxation. Under direct taxation schemes the government acquires money from the public directly. Through inflation the government uses its monopoly on the supply of money to create new money or to receive newly created money from a legally privileged banking system. ${ }^{3}$ The government can buy resources from the public with the new money, thus bidding up prices and imposing an implicit cost on the public. Resources are transferred from the public to the government in a similar manner to direct taxation. ${ }^{4}$ In both cases the public has command over fewer resources 
and the government over more.

This paper sheds light on the role of inflation in government finance and the effects thereof. It starts by looking at the causes of inflation, specifically focusing on its use as a form of taxation. The effects of inflation - both economic and ethical - will be outlined, along with corresponding methods to evade or avoid these results. Finally we will assess some legal implications of avoiding inflation and conclude with a look at the benefits and costs that accrue to individuals who do so.

\section{Inflation- Veiled and Costly}

Although inflation has a storied history among economists, focus on its legitimacy has been insignificant (Balac 2008; Hülsmann 2008; Bagus et al 2011). Writing in the late $16^{\text {th }}$ century, the Spanish scholastic Juan de Mariana outlined the coercive nature of inflation (Huerta de Soto 1999: 6). David Hume's monetary writings in the $18^{\text {th }}$ century assessed unit changes of the monetary stock as valuational changes that affect the unit value of other individuals' money holdings (Hume 1970). More recently, Hülsmann (2008) and Howden (2010a) have delved into the history of relations between monetary economics and ethics. It is, however unfortunate, not too surprising that there has been a general neglect for attention heeded to ethical implications of inflation. As Hülsmann (2008: 87) explains:

Economists are reluctant to dwell on the moral dimensions of social facts, and rightly so, because moral questions are outside their customary purview. But one does not need to be a moral philosopher to know that certain incomes are illegitimate; that they derive from a violation of the fundamental rule of society. ${ }^{5}$ 
Monetary economists are especially well-suited for analyzing inflation as they understand the process by which it originates and later propagates throughout the economy. A background in this knowledge is essential prior to assessing the methods to and legitimacy of evading such a tax.

Inflation propagates through two different ways - one at its inception, and one ongoing. We must first assess the process through which a fiat money guaranteed by legal tender status replaces the existing commodity money in circulation. This is typically achieved with force or threat thereof (Rothbard 2008). When Franklin Roosevelt signed executive order 6102 on April $5^{\text {th }} 1933$, U.S. citizens where effectively "forbidden [from] the Hoarding of Gold Coin, Gold Bullion and Gold Certificates." Violators were treated under the "Trading with the Enemy" Act of 1917 (later amended in 1933) and subject to a fine of up to $\$ 10,000$ or ten years in prison, or both. ${ }^{6}$ While this act effectively forbid domestic citizens from using gold as money, it was not until Richard Nixon unilaterally "closed the gold window" on August $15^{\text {th }} 1971$ that foreign governments were barred from redeeming U.S. dollars into gold bullion. The U.S. dollar had officially been transferred to a fiat standard under the coercive threat of fines and imprisonment. It is under the security of legal tender laws that inflation becomes coercive in a similar manner to direct taxes. As an individual is obliged to use the preferred money unit by law, he is unable to easily (or legally, in some cases) avoid incurring the effects of inflation.

Legal tender status guarantees the continued existence of a fiat money (Frank Chodorov 1954: 42-43). The advantage of a guaranteed demand is created by making a currency acceptable in the settlement of all public and private debts. Even if the legal tender status is only applicable to public debts, the induced demand for money for the payment of taxes (which are, after all, the 
only other certainty after death) creates a desire for private agents to accept the same money in settlement of private debts as well. This gives the fiat currency, although not officially imposed on the market, a competitive advantage over its potential rivals.

A monopoly monetary system imposing inflation and its associated tax has been regarded as illegitimate (Walter Block 1991, Rothbard 1998, and Hoppe 2006 assess the legitimacy of imposed orders). If the expropriation of a favored money has occurred, such as occurred in America in 1933 and 1971, actions to evade this expropriation must also be supported. While 1933 and 1971 represent two clear examples of this monetary expropriation, an ongoing tax via inflation achieves the same effect. Inflation, while redistributing purchasing power from the public to the monetary authority, leads to three main results.

First, there is a redistribution implicit in any process that changes the money supply. Newly created money is injected into the economy at specific places and spreads slowly to individuals' cash balances, bidding up prices (Richard Cantillon 1959). Depending on the preferences of the first receivers of money, relative prices will change as some prices rise faster than others. There is a redistribution from the last receivers of the new money to the first receivers. Those individuals who receive the new money units last will see their costs rise faster than their incomes compared to those who receive the new money first and see their incomes rise faster than their costs. Inflation allows the government and the first recipients of government spending to profit at the expense of late receivers of the newly created money. ${ }^{7}$

A second cost is imposed on a group of specific market participants - savers - who forgo consumption in the present in hopes that their savings can grow to satisfy a greater future level of expenditure. Their plans are frustrated as inflation erodes the future purchasing power of their savings. Those on fixed incomes, typically pensioners or the unemployed, are likewise hurt. ${ }^{8}$ As 
their budget is constrained by accumulated savings, the only way to increase future purchasing power is through healthy investment returns. Inflation reduces real profits (i.e., those reckoned in terms of purchasing power), thus disturbing their ability to consume at a predefined level. Inflation promotes consumption as an additional cost on savings makes this activity relatively less attractive. ${ }^{9}$

Third, savers and investors are disconnected from each other. Inflation is generally defined as an increase in the money supply (Rothbard 2008: 43-44; 2009: 809, 913; Mises 1971: 239-241, 272 and in passim). This increased money supply often coincides with a credit expansion of the banking system. As the central bank and private banking sectors often purchase government bonds, the monetary base multiplies when banks expand credit upon the newly created reserves. This credit expansion may distort interest rates and lead to more investments than there have been real savings. As successful long-term investments can only be undertaken consistent with real savings, a boom-bust cycle may set in. ${ }^{10}$

While these three negative results of inflation are well known, their causes deserve quick mention. As inflation is defined as any increase in the money supply, its effects stem from two fundamental sources.

First, a centralized agency may create money ex nihilo if it has a monopoly over the issuance of money. This is typically the case today with national central banks with this monopoly power endowed by their respective governments. Backed by legal tender laws ensuring the acceptance of their notes, these banks can augment the money supply with an assurance that there will be an assured demand.

Second, a fractional-reserve banking system can increase the money supply endogenously (Bagus and Howden 2010; 2012a; 2012b). By allowing banks to hold only a 
portion (or fraction) of their demand deposits as reserves, a greater amount of deposits are issued than currency exists to cover.

Before delving into the effective means to reduce the overall burden of inflation on society, we must comment on a method of evasion that serves to merely redistribute its burden. Individuals reducing their saving rates in favor of increased consumption expenditures can mitigate the burden of inflation. ${ }^{11}$ As inflation cannot reduce the purchasing power of something that is not there, no inflationary loss can directly ensue. While this avoids the first-order effects of the tax, it misses a more salient point. A second-order reduction of purchasing power results in part due to the increase in consumption expenditures. As more money is dedicated towards the purchase of consumer goods, their prices are bid up accordingly. At the higher price level, the existing pool of savings will be able to purchase only a reduced amount of goods. The result is that a secondary inflationary effect will still detriment savers.

No progressive tax can be considered neutral in the sense that it benefits or harms all individuals equally (Hayek 1960: 314). Likewise, an evasion of inflation by increasing consumption expenditures will benefit those who initially spend, while those who prefer to continue saving will see a continual erosion in their purchasing power (Bagus and Howden 2011; 2013). Not only is inflation itself highly unequal and redistributive, but its evasion can also exacerbate these results. Inflation thus has the same result as a general tax (Maurice Allais 1993: 331) and its evasion places a secondary tax on those unknowing of its presence or reacting less quickly to it. The burden of inflation shifts from those who spend faster and in increased amounts onto those who spend more slowly or in smaller increments.

Not all affected individuals can feel the effects of this evasion equally. It may be obvious that depending on one's role in the inflationary process - as either the creators of inflation or 
innocent bystanders -the benefits and costs will be asymmetrical (Mises 1998: 412).

Lower-income individuals typically bear a larger burden of inflation than their higherincome counterparts (Andrés Erosa and Gustavo Ventura 2002). Wealthier individuals are usually better situated to avoid any tax as they tend to have both the knowledge and resources to do so. They may invest a larger portion of their earnings (as a percentage) in higher earning assets, thus retaining the ability to save in the face of a general decline of purchasing power. Lower-income individuals can pursue similar strategies, to the extent that index funds or inflation-indexed bonds are available. Yet because they have a smaller portion of their income available for investment purposes they will have an offsetting larger portion of their income negatively affected through inflation on the prices of goods there are purchasing. While financial products exist to minimize the effects of inflation on one's investments, it is difficult (if not impossible) to employ a similar strategy to protect one from the increasing prices of their consumables.

Tax accountants are well noted for their ability to aid the wealthy in evading more direct taxation schemes. In the same sense, savvy financial planners are able to direct clients' savings into plans that offer competitive inflation-adjusted returns, thus better evading any inflationary effects on their wealth. Knowledge of wealth management is generally higher among the wealthy than the lower-income portion of society. This leads to a greater awareness of the existence of inflationary loses of purchasing power, as well as increased attention towards mitigating its effects. Finally, wealthy individuals are usually among the earlier receivers of an increased money supply (whether for investment purposes or through purchases by investment firms that gain early access to the funds). ${ }^{12}$ As a result they are better situated to take advantage of the increased money supply prior to any upward pressure on the general price level (which they will create through their spending). 
While direct taxation operates under the pretense of helping lower-income individuals through redistribution effects, inflation is constrained under no such mandate. In fact, it is unclear who, exactly, inflation is supposed to benefit. Detrimental consequences fall most heavily on those shoulders that are generally regarded as the most in need of help - the lower income brackets of society. More egregiously, these detrimental consequences are felt, to some degree or another, by all market actors; purchasing power losses cannot be evaded. The only group to benefit from this process is the ultimate producer of money - the government's monetary authority, a monetary institution endowed with a state-granted monopoly privilege over the nation's money supply, or a bank permitted to operate with only fractional reserves.

Far from only harming private individuals, inflation also has the ability to reap harm to the party creating and primarily benefiting from it - the government. Cases of hyperinflation, for example, have historically caused a loss of legitimacy in the government. Weimar Republic Germany is a case in point (Bresciani-Turroni 1937). As price inflation picked up in the early 1920s, German people started to evade the pernicious effects of the inflationary tax. Conditions reached the point where Germans began spending their incomes immediately as they received it; prices skyrocketed. Indeed, prices rose in some stages of the hyperinflation much faster than the increase in the money supply. At these high prices, there was a perceived "shortage of money." This "shortage of money" induced the German central bank, the Reichsbank, to print even more money to keep up with rising prices, to no avail.

The collapse of the monetary system led to severe social problems. A society where you could get rich by speculating in a few weeks and poor by saving and adhering to traditional values seemed to have no principles. The surge of all types of radical political forces in the wake of the inflation undermined the Weimar Republic. Indeed, the hyperinflation may be partially 
responsible for Hitler's rise to power.

While the example of Weimar Germany and the collapse of the German government is instructive, it is a rare event. While individuals have a clear incentive to evade inflation to retain their purchasing power, for the government the incentives differ. The emphasis here is on pursuing rates which do not cause alarm as to the extent of the loss in purchasing power and otherwise cause social unrest. Long periods of sustained inflation have resulted in little backlash provided that the rate is sufficiently low and, perhaps more importantly, steady so as to pass unnoticed by most members of society.

\section{Three methods of avoidance}

Avoidance of taxes has long been supported if it is proven that these taxes are coercive and disruptive in nature. However, little explicit support for the avoidance of inflation exists, likely a result of its veiled nature. However, given the complexities of money's role in the economy, there are three ways that this avoidance can be achieved. Money has three primary functions - it acts as a medium of exchange, a store of value and a unit of account. Each of these roles can be used to avoid inflation and thus preserve the purchasing power of savings, as well as allow for increased ease of economic calculation through steady prices. Money's three roles also allow for three distinct means that we may use to avoid inflation without merely redistributing the burden as in the case of shifting savings into consumption expenditure.

The first method to avoid inflation is via money's unit of account function. The unit of account is that good that we commonly define prices in. Goods are priced in dollars in the United States, or euros in the Eurozone. Inflation adds costs to producers as the real value of the money they receive in exchange for their goods declines. As a result, they must continually change 
prices to reflect this change, an outcome commonly referred to as a "menu cost." Alternatively, consumers must make more frequent withdrawals of their money as it loses value, leading economists to assign the term "shoe leather costs" to reflect the expenses from making additional withdrawals. Most importantly, monetary calculation (accounting) requires a currency that is not subject to violent fluctuations in purchasing power (Mises 1998: 424-26). When the crucial tool of monetary calculation loses its stability, economic planning is severely hampered. Without a reliable unit of account, planning errors - both financial and production-based - increase.

These costs can be avoided easily by denominating goods, services and contracts in a good other than the one issued by the central monetary authority. Defining prices in a commodity (such as gold), or a composite bundle of commodities, can bring stability to prices not available under most imposed fiat money regimes. The benefits of such an option are more pronounced on longer-dated loan contracts, as the effects of inflation compound over time. As an example of how this alternative would operate, consider a simple mortgage transaction. In today's world, an individual borrows $\$ 150,000$ today to purchase a house, and must pay this off over the ensuing 30 years. The bank is at great risk, as it must estimate what the rate of inflation will be over those 30 years, lest it lose by being repaid in less valuable money units than it originally reckoned. To compensate for this risk, a premium is included in the interest rate charged based on the expected loss of purchasing power of the money lent. Since this inflation premium is agreed to based on the expected inflation rate, the bank will earn a higher return if actual inflation is less than expected, and the borrower will gain if inflation is higher than originally reckoned. Many resources are dedicated to determining what the actual rate of inflation will be in a bid to avoid the costs of being on the "losing end" of the loan.

Now consider that the mortgage could be denominated in a commodity of more-or-less 
stable long-term value, e.g., gold. If gold was selling at $\$ 1,500 / \mathrm{oz}$. when the mortgage was contracted, this would imply that $100 \mathrm{oz}$. of gold were borrowed. The homeowner will need to pay the bank the equivalent value of these $100 \mathrm{oz}$. of gold over the next 30 years, thus protecting the bank from any inflation eroding the value of the money unit. It is true that changes in the value of gold will alter the final cost of the mortgage, and that unexpected increases in the price of gold will benefit the bank, while a drop in the gold price will allow the borrower to pay off the loan at lower cost. What is relevant is not whether using a commodity such as gold to denominate long-term contracts will completely eliminate the costs of setting the terms of the contract, but whether it allows so at a lower cost than the alternative. Using a commodity standard has the advantage of avoiding price changes due to the potential political machinations of the central bank, and studies also suggest that for time horizons longer than 30 years, gold provides a less volatile pricing unit than U.S. dollars (Bordo et al. 2003).

In extreme cases like the German hyperinflation of 1923, people started to calculate in gold marks or dollars instead of the legal tender "Reichsmark" in order to evade this effect of inflation (Wilhelm Röpke 1937: 103-04). In more subdued cases of inflation - ones where the rate is merely high but sustained - countries often experience a shift toward the use of foreign currency to serve money's three roles (Carmen M. Reinhart and Kenneth S. Rogoff 2009: 191). Defining prices in terms of a commodity may solve the apparent problem of a long-term loss of purchasing power but at the expense of having to endure short-term volatility. Indeed, in this regard the one advantage that money has as a pricing unit is that its purchasing power can be expressed in terms of all other goods. As a result the volatility of money prices is generally quite low, allowing for stealth inflation to reduce money holders' purchasing power unbeknownst to them over even shorter periods of time. 
Defining prices in terms of the value of a basket of goods allows for an alternative to using money as a pricing unit while not incurring undue volatility. Many monetary reform plans center around this key idea. Money could still circulate as a medium of exchange if people wanted, but all prices would be defined in terms of an abstract unit. Greenfield and Yeager (1983) recommend a pricing unit defined in the price that results from a basket of goods, for example, a basket comprised of equal parts of lumber, zinc, bread and apples. As the prices of these goods are not perfectly correlated the result is a unit of account of more stable value than any individual component (such as in the previous example using gold as the only unit to denominate the contract). Using such a system would tend to stabilize the expected price of the dollar-defining bundle (Woolsey 1994). Investors are already able to define many financial contracts in a similar way. The Stable Currency Benchmark (SCB) is a pricing unit comprised of several negatively correlated major currencies - U.S. dollars, New Zealand dollars, Singapore dollars and Swiss francs- which retains its international purchasing power well. In both of these schemes purchasing power losses from inflation are avoided while the volatility of the alternative is minimized.

Second, the store of value is that good that we use to preserve the future purchasing power of our savings. It is also the monetary function most affected by inflation. As the future purchasing power of savings is reduced, a wealth transfer from savers to consumers occurs. Fortunately, it is also the easiest function to use to avoid such a tax. Savings can be, and often are, held in an inflation hedge - a countercyclical asset that increases in value as the purchasing power of the monetary unit decreases to avoid this tax (houses and gold spring to mind quickly as traditional hedges, but examples abound).

We require a store of value that allows us to maintain the value of our production until 
that moment comes when we desire to spend the proceeds. We typically prefer a monetary unit that retains its value over time, i.e., acts as a good store of value, to one that does not. In the modern economy, the store of value function has already been separated from the legal tender money in order to avoid inflation. Different goods have replaced legal tender money to preserve wealth and retain an individual's purchasing power. By reducing cash holdings to a minimum, an individual substitutes savings away from cash and into a good that acts as a more optimal store of value. Again, gold may serve as the medium that we save our earnings in. Historically gold has preserved its purchasing power extremely well over long periods, allowing it to purchase a similar amount of goods today as several hundred years ago. As we will see in conjunction with the next method, people may also start to exchange this store of wealth directly in some transactions, instead of using a currency that suffers from purchasing power losses.

Last, those old dingy notes in our wallets or the change jingling in our pockets embody the medium of exchange function. The medium of exchange is that good that we renunciate to a seller when we make a purchase. This is where the most evident effects of inflation result. As a central bank generally controls the supply of the medium of exchange directly, its purchasing power is potentially subject to large variation. Every good economist knows that "a dollar today is worth more than a dollar tomorrow." While we always prefer the certainty of a dollar sooner than later, it is also worth more as the general tendency under a monopolized currency is to inflate the currency's value away thus reducing the value of a dollar tomorrow. We call the profit earned from such an action seigniorage, and it represents that amount of taxation taken from savers and given to the money-issuing authority. This function is more difficult to avoid, as it requires using a medium of exchange different from the one being inflated.

A good is chosen, or evolves, as money to eliminate the "double coincidence of wants 
problem" (Carl Menger 1892). In short, money allows us to trade easily with partners who do not directly desire what we have to offer. Money serves as an intermediary, greasing the wheels of commerce and trade. Abandoning the general medium of exchange in favor of another good requires that both parties agree upon the alternate good. This may prove difficult in practice.

In a spontaneous process of trial and error, the avoidance of inflation may lead to the selection of a money that better fulfills its three functions. Inflation avoidance thereby fulfills a crucial social function benefitting third parties: it may lead to a more stable and sound medium of exchange, reduce the risk of business cycles, foster savings, and facilitate economic calculation and growth. An individual will only be motivated to avoid inflation when the perceived benefits outweigh the costs. As the ultimate cure for inflation is to rid the monetary system of inflation this realization helps to explain why so much ire is directed at direct taxation (and so many resources expended avoiding it) while so little is afforded to inflation. Using the rate of price inflation as a proxy for the rate of the tax, we can see that in most Western countries it has been low (around 3\%) and stable for several decades. The corresponding gains from efforts aimed at circumventing "paying" such a tax are relatively low compared to those that can be gained by avoiding or evading direct taxes.

The gains from moving to a new currency will not be uniform throughout the population. Since savers lose from inflation more than consumers we would expect the adoption of a new currency as driven, or at least started, by the former group rather than the latter. In this regard, evading inflation tends to be a policy pursued by the same group of individuals that commonly evade or avoid direct taxes. Individuals who have built up wealth through effective investments of their savings have more at stake by evading taxes in the present, both in terms of preserving their existing wealth and promoting a greater rate of return on future investments. While some 
individuals will have an incentive to shift to a new money, as in Hayek (1976), it is true that there are costs to doing so. Network effects, for example, may prove insurmountable for lower income individuals to overcome, and thus demotivate them from searching for a less inflationary type of money (as in Friedman 1984).

Increasingly network effects are becoming less important for day-to-day transactions. Low foreign-exchange fees and the ease of electronic money transfers make it relatively easy for an individual to hold his money in a different currency and still use it to settle debt obligations and general transactions. New innovations, such as bitcoin, have also contributed to the cost effectiveness of other forms of money and thus lessened the engrained nature of established currencies by reducing their network cost-based advantage. While wealthier individuals may be amongst the first users of such new developments, by making the shift they reduce the costs for other later adopters. As the network of individuals using an inflationary money slowly diminishes the costs of shifting to an alternative also fall. The result is that with every individual who decides to make use of an alternative money the rest of the users of the old money also see a diminished cost and an added incentive to make the shift.

A functioning monetary system is the basis for an extended division of labor and a complex society in need of sophisticated economic calculation and long-term planning (Mises 1998: 230-32). When money stops to fulfill its functions sufficiently due to inflation, tax evasion is one solution to the problem. Inflation avoidance may improve the foundation of the monetary system and help to preserve it. At the extreme, the preservation of the monetary system preserves our civilization which, based on the division of labor, is able to feed seven billion people. In other words, inflation avoidance strengthens the foundations of civilization and may save billions of lives. 


\section{Legal Complications}

In each of the three cases listed above, there are no legal complications to avoiding inflation. In most Western countries, the only law relevant to money's use is a legal tender law. This generally forces a merchant to accept a specified money in payment, but allows for each of the aforementioned avoidance options. Individuals can denominate contracts in different goods, accept goods other than "money" to settle debts, and even pay in a non-money good (provided the other party of the transaction accepts it). Thus, there is no insurmountable legal barrier involved in avoiding inflation by using a nonmonetary good for each of money's three functions.

The legal setting of the tax's avoidance has, however, little bearing on its legitimacy. One cannot resort to answering the question: "why is taxation morally permissible, while other types of compulsion are not?" with the answer: "because it is legal" (Bagus et al 2011). To do so falls prey to the petitio principii fallacy - namely, that one cannot base their argumentation on a conclusion. One must instead evaluate the legality on either a normative or positive basis to achieve an assessment of legitimacy.

The legality of a process does not make it ipso facto just (Paul Groarke 2004). If it did, regimes such as slavery would have to be deemed just, provided that they exist confined to an accepting legal jurisdiction. ${ }^{13}$ Legal tender laws, as they exist in much of the world today, make only some methods of avoiding inflation illegal. This opens them up to greater ease at avoidance in the face of the predefined illegitimacy. In fact, people have already started to use alternative currencies offered by companies such as e-gold or bitcoin, effectively avoiding some of the costs of inflation. Gradually inflation may be avoided more and more by these and other market-based solutions. ${ }^{14}$ 


\section{Conclusion}

It is difficult to justify inflation from an ethical point of view. Utilitarians will well note that the punitive damages caused by inflation (regressive wealth transfers and the instigation of the business cycle) outweigh the alleged benefits which are primarily limited to reducing the real

value of debt owed. ${ }^{15}$ Natural rights theorists must accept that inflation is a form of taxation, and as such are left in a position that if they view direct taxation as an involuntary redistribution of wealth they must view the result of inflation as the same. Kant's categorical imperative suggests that even low levels of inflation must be ethically suspect. There is a general disdain for the redistributions and loss of wealth apparent during hyperinflationary situations, such as the recent episode in Zimbabwe. Yet this is only a difference of magnitude and not of kind relative to the lower levels of inflation experienced today by almost all developed countries. If the original basis of inflation cannot be justified, avoiding paying it cannot be considered ethically suspect. Money's three distinct roles - as medium of exchange, store of value and unit of account - allow for three methods to avoid paying such a tax.

Striking contracts in terms of a good other than the good being inflated allow the relevant parties to avoid valuational changes due to inflation. Using an alternative good (or basket of goods) as a unit of account allows an individual to ensure future cash flows retain their real value. Holding savings in the form of a good distinct from the inflated currency also allows one to avoid purchasing power loses. Investors often pursue this option today - knowingly or not - as individuals hold assets in goods that act as inflation hedges.

There are however some practical problems to avoiding inflation, especially concerning the medium of exchange function of money. People must accept the legal tender money for 
settlement of contracts, even though the contract is denominated in another good. When, for instance, a loan has been contracted in ounces of gold, the debtor has the right to pay the loan back in fiat dollars. This leads to a significant increase in legal uncertainty. Moreover, experiments to introduce alternative media of exchange encounter another difficulty due to the important network effects of money. As the government demands the legal tender money through its direct taxation and spends it later, it creates an important demand and use for the legal tender money. Due to the sheer size of the government in the economy and the engrained network effects of media of exchange, it is difficult to introduce a competing medium of exchange in order to avoid inflation.

Although difficult to evade in practice, avoiding inflation is far from impossible (Hülsmann 2008: 97-98). As in other walks of life, vigilance against unscrupulous individuals debasing or inflating a currency is necessary. A population aware of the circumstances surrounding inflation, and who properly regard it as a tax, will be more likely to search for alternatives to evade it. We have demonstrated three ways to do so that not only aid in aligning preferences to enhance welfare, but also raise no significant legal issues in most modern economies.

\section{References}

Allais, Maurice. 1993. Les conditions monétaires d'une économie de marchés: des enseignements du passé aux réformes de demain. Revue d'économie politique 3: 319-67.

Bagus, Philipp. 2008. Monetary Policy as Bad Medicine: The Volatile Relationship Between Business Cycles and Asset Prices. Review of Austrian Economics 21(4): 283-400.

Bagus, Philipp, Walter Block, Marian Eabrasu, David Howden, and Jérémie Rostan. 2011. The Ethics of Tax Evasion. Business and Society Review 116(3): 375-401. 
Bagus, Philipp, and David Howden. 2009. The Legitimacy of Loan Maturity Mismatching: A Risky, but not Fraudulent, Undertaking. Journal of Business Ethics 90(3): 399-406.

Bagus, Philipp, and David Howden. 2010. Fractional Reserve Free Banking: Some Quibbles. Quarterly Journal of Austrian Economics 13(4): 29-55.

Bagus, Philipp, and David Howden. 2011. Unanswered Quibbles with Fractional Reserve Free Banking. Libertarian Papers 3(18): 1-24.

Bagus, Philipp, and David Howden. 2012a. Monetary Equilibrium and Price Stickiness: A Rejoinder. Review of Austrian Economics 25(3): 271-77.

Bagus, Philipp, and David Howden. 2012b. The Continuing Continuum Problem and Future Goods. The Journal of Business Ethics 106(3): 295-300.

Bagus, Philipp, and David Howden. 2013. Some Ethical Dilemmas with Modern Banking. Business Ethics: A European Review 22(3): 235-45.

Balac, Zoran. 2008. Monetary Inflation's Effect on Wealth Inequality: An Austrian Analysis. Quarterly Journal of Austrian Economics 11: 1-17.

Block, Walter. 1991. Defending the Undefendable. San Francisco, CA: Fox \& Wilkes.

Bordo, Michael D., Robert D. Dittmar, and William T. Gavin. 2003. Gold, Fiat Money, and Price Stability. NBER working paper no. 10171.

Boyd, David. 2009. Ethical Determinants of Generations X and Y. Journal of Business Ethics 93(3): 465-69.

Bresciani-Turroni, Constantino. 1937. The Economics of Inflation: A Study of Currency Depreciation in Post-War Germany. London: Allen and Unwin.

Cantillon, Richard. 1959. Essay on the Nature of Trade in General, (ed. and trans.) Henry Higgs. London: Frank Cass and Co.

Cebula, Richard, and Chris Paul. 2000. The Pedagogy of tax evasion: Its extent and determinants. International Advances in Economic Research 6(4): 710-721.

Chodorov, Frank. 1954. The Income Tax: Root of all Evil. New York: The Devin-Adair Company.

Erosa, Andrés and Gustavo Ventura. 2002. On Inflation as a Regressive Consumption Tax. Journal of Monetary Economics 49(4): 761-795. 
Eabrasu, Marian. 2012. "Towards a Convergence of the Ethics of Tax Evasion and Secession." In The Ethics of Tax Evasion: Perspectives in Theory and Practice, (ed.) Robert W. McGee, pp. 107-24. New York: Springer

Friedman, Milton. 1984. "Currency Competition: A Skeptical View.” In Currency Competition and Monetary Union, P. Salin, (ed.), pp. 42-47. Hague: Martinus Nijhoff.

Garrison Roger W. 2001. Time and Money: The Macroeconomics of Capital Structure. London: Routledge.

Greenfield, Robert, and Leland B. Yeager. 1983. A Laissez-Faire Approach to Monetary Stability. Journal of Money, Credit and Banking 15(3): 302-15.

Groarke, Paul. 2004. Dividing the State. Legitimacy, Secession and the Doctrine of Oppression. Ashgate Publishing.

Hayek, Friedrich A. 1960. The Constitution of Liberty. Chicago: University of Chicago Press.

Hayek, Friedrich A. 1976. Denationalisation of Money. London: Institute of Economic Affairs.

Hayek, F. A. 2008. Price and Production and Other Works: F. A. Hayek on Money, the Business Cycle, and the Gold Standard, (ed.) Joseph T. Salerno. Auburn, AL: Ludwig von Mises Institute.

Hazlitt, Henry. 1959. The Failure of the "New Economics. Princeton, N.J.: D. Van Nostrand.

Horwitz, Steven. 2003. The Costs of Inflation Revisited. The Review of Austrian Economics 16(1): 77-95.

Howden, David. 2008. Stability of Gold Standard and Its Selected Consequences: A Comment. Procesos de Mercado: Revista Europea de Economía Política 5(1): 159-175.

Howden, David. 2010a. "Ethics and Monetary Theory: Is There a Common Middle Ground?" Ethics \& Politics 12(2): 355-66.

Howden, David. 2010b. Knowledge Shifts and the Business Cycle: When Boom Turns to Bust. Review of Austrian Economics 23(2): 165-82.

Howden, David. 2011. “Europe's Unemployment Crisis: Some Hidden Relief?”, in Institutions in Crisis: European Perspectives on the Recession, (ed.) David Howden, pp. 56-75. Cheltenham, UK and Northampton, MA: Edward Elgar.

Huerta de Soto, Jesús. 1999. Juan de Mariana: the Influence of the Spanish Scholastics”, in 15 Great Austrian Economists, (ed.) Randall H. Holcombe, pp. 1-13, Auburn, AL.: Ludwig von Mises Institute. 
Huerta de Soto, Jesús. 2006. Money, Bank Credit and Economic Cycles (trans.) Melinda Stroup. Auburn, AL: Ludwig von Mises Institute.

Hülsmann, Jörg Guido. 1998. Toward a General Theory of Error Cycles. Quarterly Journal of Austrian Economics 1(4): 1-23.

Hülsmann, Jörg Guido. 2008. The Ethics of Money Production. Auburn, AL: Ludwig von Mises Institute.

Hume, David. 1970. Writings on Economics, (ed.) Eugene Rotwein. Madison, WI: University of Wisconsin Press.

Kearl, J. R. 1977. Do Entitlements Imply that Taxation is Theft? Philosophy and Public Affairs 7(1): 74-81.

McGee, Robert W. 2012a. "Age and the Ethics of Tax Evasion." In The Ethics of Tax Evasion: Perspectives in Theory and Practice, (ed.) Robert W. McGee, pp. 441-50. New York: Springer.

McGee, Robert W. 2012b. "An Analysis of Some Arguments." In The Ethics of Tax Evasion: Perspectives in Theory and Practice, (ed.) Robert W. McGee, pp. 47-72. New York: Springer.

McGee, Robert W (ed.). 2012c. The Ethics of Tax Evasion: Perspectives in Theory and Practice. New York: Springer.

Menger, Carl. 1892. On the Origins of Money. Economic Journal 2: 239-55.

Mises, Ludwig von. [1912] 1971. The Theory of Money and Credit, (trans.) H. E. Batson. Irvington-on-Hudson, New York: Foundation for Economic Education.

Mises, Ludwig von. [1949] 1998. Human Action, Scholar's edition. Auburn, AL: Ludwig von Mises Institute.

Reinhart, Carmen M., and Kenneth S. Rogoff. 2009. This Time is Different: Eight Centuries of Financial Folly. Princeton and Oxford: Princeton University Press.

Röpke, Wilhelm. [1937] (1963). Economics of the Free Society, trans. P. M. Boarman. Chicago: Henry Regnery Company.

Rothbard, Murray N. [1962] 2009. Man, Economy, and State, Scholar's Edition. Auburn, AL: Ludwig von Mises Institute.

Rothbard, Murray N. [1963] 2000. America's Great Depression. Auburn, AL: Ludwig von Mises Institute.

Rothbard, Murray N. [1963] 2008. What Has Government Done With Our Money? Auburn, AL: Ludwig von Mises Institute. 
Roubini, Nouriel, and Xavier Sala-i-Martin. 1992. A Growth Model of Inflation, Tax Evasion, and Financial Repression. Journal of Monetary Economics 35:275-301.

\author{
Slemrod, Joel. 2007. Cheating Ourselves: The Economics of Tax Evasion. Journal of Economic \\ Perspectives 21(1): 35-48.
}

Tebbit, Mark. 2000. Philosophy of Law: An Introduction. New York: Routledge.

Torgler Benno, and Friedrich Schneider. 2007. Shadow economy, tax morale governance and institutional quality: A panel analysis. CESifo working paper no. 1923.

Woolsey, W. William. Stabilizing the Expected Price Level in a BFH Payments System. Contemporary Economic Policy 12(2): 46-54.

\footnotetext{
${ }^{1}$ We would like to thank two referees for invaluable suggestions. All remaining errors are our own.

Kearl (1977) points out that it is a logical impossibility that the effects of taxation could be neutral. Only in those cases where the tax revenue extracted is identical to the amount that would have given voluntarily and it is used to fund projects that would also have been voluntarily supported could we imagine taxation as being equivalent to voluntary exchange. In light of the fact that an individual does not voluntarily give money to these specific programs, and instead remits it to the government shows us via demonstrated preference that the act of taxation implements different projects at different levels of funding than would have been voluntarily achieved.

Jesús Huerta de Soto (2006) explicates the invasions of legal norms practiced by the banking sector as a normal state of affairs. Bagus and David Howden $(2009 ; 2013)$ have elaborated on these points, furthering the arguments made for deposit banks to the arena of investment banks as well.

Direct expropriation of goods and services may be regarded as a more immediate form of taxation where the monetary system is circumvented. In fact, there are three basic forms of expropriation of resources by the government, which vary in their degree of directness or openness. Expropriation is the most direct and open transfer of resources from the public to the government. Taxation via the coercive transfer of monetary units is less direct as the government uses the medium of exchange to acquire the resources it wants. Finally, inflation is the most indirect form of transfer of resources to the government. By the creation of new monetary units, purchasing power transfers to the government, even though the public does not lose any nominal amount of monetary units.

$5 \quad$ It is debatable whether tax issues are in actuality moral issues. McGee (2012b) notes that morality can only exist when there is a choice. Given the compulsory nature of taxation paying or evading can be neither moral or immoral.

$6 \quad$ Indexed for inflation, the fine is equivalent to over $\$ 165,000$ today.

${ }^{7}$ Henry Hazlitt (1959: 278) discusses the loss in purchasing power for wage earners during inflationary periods and the subsequent redistribution effects. Bagus and Howden (2012a:272-74) look at the asymmetrical effects of inflation stemming from both central bank created base money and private bank created money through fractional reserves.

${ }^{8}$ A negative opinion of the income tax may vary depending on one's demographic, as the effects felt are asymmetrical. David Boyd (2009) focuses on the differences between Generations X and Y concerning their ethical concerns. While these two closely related groups are shown to have drastically distinct ethical norms, the differences may become increasingly magnified as we focus on an even more distinct group - the elderly, as the example of the fixed-income group par excellence - and their attitudes towards the ethical concerns of inflation. McGee (2012a) finds that older citizens are more opposed to tax evasion than younger people, in a cross-sectional analysis of 12 countries.

9 Inflation leads to a tendency for consumption to increase in relation to savings. The final outcome of the consumption to savings ratio depends on the time preferences of the first receivers of the newly created money. When government expenditures are mainly on welfare programs and recipients with a relatively high time
} 
preference, the consumption to savings ratio is further increased.

${ }_{10} \quad$ See, for example, Ludwig von Mises (1971; 1998), Hülsmann (1998), Rothbard (2000; 2009), Roger

Garrison (2001), Bagus (2008), Friedrich Hayek (2008), Huerta de Soto (2009), Howden (2010b) for the

relationship between the business cycle and inflationary monetary policies. Steven Horwitz (2003) argues that disrupted prices that cause business cycles are often neglected when assessing the costs of inflation, resulting in an understatement of the full economic cost of the practice.

${ }_{11}$ Inflation results in an artificially high level of "time preference" - the preference for present consumption over growth-enhancing savings (Hoppe 2006: 36; Hülsmann 2008). Savings can also be held in an asset class acting as an inflationary hedge to avoid purchasing power losses (gold is the classic example, but inflation-indexed bonds also abound today).

12 Governments can maximize their tax revenue by repressing financial innovation (Nouriel Roubini and Xavier Sala-i-Martin 1995). By reducing private financial alternatives, an increase in demand for government issued money results, with the result that an increase in inflation revenue (or seigniorage) will be obtained - one alternative to evading inflation will be eliminated.

13 Even if legal rules are found valid by the court system of a given jurisdiction, there is still a question of one's moral duty to obey questionable laws. "Is the claim that a law is valid equivalent to the claim that it is morally valid and justifiable?" (Mark Tebbit 2000: 37).

14 Until such a time that market-based solutions become readily available, the underground economy may continue to flourish to evade inflation. Richard Cebula and Chris Paul (2000) assess the the United States, Howden (2011) assess the euro zone, and Torgler and Friedrich Schneider (2007) assess a cross-section of countries, finding a high correlation between the size of the underground economy and the size of the taxes prevailing. While much attention is paid to illegal activity that results in high direct taxation schemes, little attention has been previously afforded to inflation tax evasion that results in "black market" activity. In a similar vein, Marian Eabrasu (2012) notes the similarity between tax evasion and secession. Avoiding an income tax via an exit from the formal economy, or by renunciating the use of the legal tender currency in many ways amount to a secession from the monetary sphere.

${ }^{15}$ Even this presumed benefit is questionable to the extent that expectations factor the future effects of inflation correctly into interest rates. 